\title{
OLGA OROZCO: LA VOZ POETICA QUE LLAMA ENTRE MUNDOS
}

\author{
POR \\ NAOMI LINDSTROM \\ University of Texas
}

Al revisar la producción poética de Olga Orozco (n. 1920, La Pampa, Argentina), que ya abarca un período de cuatro décadas (Desde lejos apareció en 1946), es posible apreciar plenamente la rapidez con que encontró, y la seguridad con que ha seguido enriqueciendo, una forma de texto adecuada a sus necesidades expresivas. Las características definidoras de este texto - su formato físico, la elección de un registro del habla y el repertorio de preocupaciones temáticas- poco o nada fluctúan con las cambiantes modas poéticas y antipoéticas. Por eso sólo se puede hablar de su trayectoria poética, como lo ha hecho muy bien Juan Liscano, trazando el aumento de complejidad que ha logrado la poeta dentro de las coordenadas ya establecidas en sus primeros textos ${ }^{1}$.

Nuestra consideración de la poesía de Orozco examina precisamente la funcionalidad de este conjunto de rasgos típicos como plasmación de un concepto del texto poético o, más precisamente, del hablar poético. La

${ }^{1}$ Juan Liscano, en su prólogo a Olga Orozco, Veintinueve poemas (Caracas: Monte Avila, 1975), pp. 9-35, «Olga Orozco y su trascendente juego poético», ofrece una buena presentación general del desarrollo poético de la autora en todos sus aspectos y emite juicios críticos, bastante sensatos, al respecto. Telma Luzzani, «Prólogo» a su compilación de Orozco, Poesía: antología (Buenos Aires: CEDAL, 1982), pp. I-X, enfoca un aspecto en particular: «Desde el comienzo, la poesía de Olga Orozco expone los núcleos de significación fundamentales que irán ahondándose a lo largo de su producción, no muy vasta pero profundamente coherente» (p. I). Stella Maris Colombo, Metáfora y cosmovisión en la poesia de Olga Orozco (Buenos Aires: Cuadernos Aletheia de Investigación y Ensayo, Grupo de Estudios Semánticos, 1983), es un examen especializado de la representación del significado. Julieta Gómez Paz, "Nostalgia del paraíso (Olga Orozco)», en su Cuatro actitudes poéticas (Buenos Aires: Conjunta Editores, 1977), pp. 51-59, es una presentación general, pero algo difícil de acceso por su lenguaje, en sí poético. 
presuposición básica es la siguiente: que el texto orozquiano ha podido mantenerse en su forma reconocible, a lo largo de casi cuarenta años, y absorbiendo las modificaciones ya descritas por Liscano, porque encarna la noción del yo poético como invocador, el individuo encargado de 1lamar a los habitantes del mundo material para percibir y establecer un contacto con "otro reino» ${ }^{2}$, y a los seres del mundo no visible para presentarse y establecer la comunicación con lo tangible. Sean espíritus o divinidades menores en el sentido tradicional o simplemente manifestaciones de los poderes intuitivos del ser humano, estas presencias sólo pueden ser invocadas por el vaso comunicante que es el rito, la invocación y la incantación. La poesía como llamada a iniciar un contacto la ha descrito Walter J. Ong en su reflexivo ensayo «Voice as Summons to Belief», título muy útil para empezar a ver este aspecto del texto orozquiano. Según Ong, «The 'evocative' quality — which is to say, the 'calling' quality - is paramount in a work of real literature. Literature exists in a context of one presence calling to another» ${ }^{3}$. En el caso de Orozco, hay que reconocer que la presencia así invitada puede ser el lector, que debe convencerse de la visión que ofrece el poema de otro mundo, como en otras ocasiones puede ser la presencia "otra» que invoca la poeta. Para dar un caso ilustrativo, la totalidad de Cantos a Berenice (1977), como indica el título, va dirigida $a$ una gata muerta, espíritu familiar de la yo, y que se supone apto para recibir un mensaje emitido desde este mundo. Es más común encontrar en los poemas de Orozco una fluctuación entre dos modalidades: la de dirigirse a un tú o ustedes materiales, lectores que necesitan los servicios de un poeta-summoner, y la de dirigirse a las fuerzas no palpables.

Para indicar cómo funciona este concepto de la poesía como llamada entre mundos conviene examinar uno de los primeros poemas de Orozco, «Quienes rondan la niebla», aparecido en Desde lejos. Hasta el comienzo de la última estrofa, la preocupación del yo es comunicar a otro - a alguien que quizá no tenga la debida conciencia de tales fenómenos- la omnipresencia de «seres... de otro cielo», «los seres que fui», que vuelven y siguen presentes no sólo mucho tiempo después de su existencia material, sino que «Siempre estarán allí».

El trabajo que debe llevar a cabo el yo durante las seis primeras estrofas es afirmar de un modo convincente la intromisión de estas «hijas de

${ }^{2}$ La cita es de Olga Orozco, «Quienes rondan la niebla», recogido en su Obra poética (Buenos Aires: Corregidor, 1979), pp. 11-12. Esta edición recopila la poesía de Orozco hasta 1977.

${ }^{3}$ Walter J. Ong, S. J., "Voice as Summons for Belief», en su The Barbarian Within and Other Fugitive Essays (New York: MacMillan, 1962), pp. 58-59. 
nuestra imagen» en el mundo material; y además, afirmarla ante un tú al parecer poco dispuesto a percibirla. El instrumento más indicado para «llamar a creer» a este tú es, según la formulación de Ong, la voz poética ${ }^{4}$.

¿A qué se debe la eficacia de esta voz, que se ha mantenido durante la carrera poética de Orozco? La característica fundamental es la ceremoniosa dignidad retórica del habla. La oratoria se despliega con una lentitud expansiva y meditante a la altura de un pronunciamiento ritual. El carácter de rito determina una serie de rasgos formales del texto de Orozco; como apunta Liscano, «El ritmo del versículo sigue siendo largo y pausado» ${ }^{5}$. En la obra posterior a Desde lejos se aumenta la morosidad deliberada con que el texto se desarrolla, patente en la extensión de los versos, muchos de los cuales traspasan el margen y necesitan un espacio adicional. Los poemas llegan a cubrir muchas veces dos páginas o más a único espacio. Algunos textos que parecen poemas en prosa podrían, con más justicia, clasificarse como extensiones del típico verso larguísimo, que en este caso no termina sino cuando llega al final del enunciado. E1 principio rector es que el poema constituye una forma de habla privilegiada, dotada de una significación especial por su capacidad de establecer contactos extraordinarios, y como tal se otorga el derecho de utilizar el espacio y el tiempo que necesite para cumplir sus propósitos. Darle al poema una mayor comprensión sería como apremiar a un sacerdote para que concluyera más rápido una ceremonia de invocación ritual.

E1 léxico que elige Orozco para aludir a «los que llegan» aumenta también la cualidad persuasiva de la afirmación central («están allí»). Un vocabulario depurado elimina la connotación espectacular o escalofriante que puede cobrar cualquier referencia a lo sobrenatural. No se habla de apariciones, p. ej., o de revenants. La posibilidad de una asociación con lo macabro o el "cuento frío» decadentista se anula por la restricción lingüista, que permite sólo ítems léxicos que podrían servir para referirse a lo no sobrenatural. Los seres aludidos en el poema son «Quienes rondan la niebla», «los seres que me aguardan», «dispersas y fieles hijas de nuestra imagen»e, individualmente, «la niña de los sueños», «la niña del olvido», etc. En varios casos, el sujeto de la oración se suprime, dejando al lector especificar de qué clase son los que «llegan» o «están».

Por otra parte, el lenguaje tampoco cae en el riesgo contrario, el de hablar de lo trascendental con una naturalidad pedestre. En «Quienes rondan la niebla», el poema perdería su carácter distintivo si los seres

\footnotetext{
${ }^{4}$ Ong, p. 59.

${ }^{5}$ Liscano, p. 20.
} 
fueran simplemente recuerdos de la infancia. Aun en la sencillez léxica de Desde lejos, ha sido posible alcanzar un nivei elevado en el registro del habla. La dignidad de la dicción poética se debe no sólo al rechazo de elementos coloquiales o excesivamente cotidianos - la antipoesía es ajena al proyecto de Orozco-, sino también a las yuxtaposiciones de vocablos cuya relación no se basa en la lógica diurna. Este recurso es, sin duda, el que ha ganado la clasificación de «surrealista» para la obra de Orozco $^{6}$, aunque tal designación poco especifica la función de tales vinculaciones sorprendentes. Recuerda, además, el vínculo entre la generación en que aparece Orozco, la del cuarenta, y su asesor Oliverio Girondo, sobreviviente del vanguardismo de los veinte ${ }^{7}$. E1 paralelismo entre Orozco y Girondo, que va mucho más allá del surrealismo atribuido a los dos, merece un estudio aparte con respecto a la producción posterior de aqué1la. En el caso de Desde lejos, basta citar algunas muestras para dar una idea del uso bien funcional - de ningún modo aleatorio- del lenguaje figurado. En «Quienes rondan la niebla», el yo nombra «los seres que fui» valiéndose de unas designaciones que afirman la realidad de los seres aludidos sin disminuir, con su tono positivo, la naturaleza extraordinaria de éstos:

la niña clara y cruel de la alegría, coronada de flores polvorientas, la niña de los sueños, con su tierno cansancio de otro cielo recién abandonado:

la niña de la soledad, buscando entre la lluvia de las alamedas el secreto del tiempo y del relámpago,

contemplando sus manos que la muerte de un árbol oscurece:

la niña del olvido que llama, llama sin reposo sobre su corazón adormecido.

La última estrofa del poema establece una característica que seguirá siendo fundamental en la producción de Orozco: el que habla en la poesía posee el derecho privilegiado de buscar una comunicación con el otro mundo, de relacionarse directamente con éste. Al contemplar otra realidad, al comentarla, al afirmar su presencia, el yo llega a percibirla como superior y más cargada de significación que la realidad cotidiana desde la que llama. Así, su llamada a los seres persistentes del pasado cobra

- Por ejemplo, Guiilermo Ara en su Suma de poesía argentina, 1538-1968 (Buenos Aires: Guadalupe, 1970), tomo 2, p. 130, califica su verso de surrealista y enfatiza los vínculos de la generación de 1940 con el surrealismo, p. 142.

${ }^{7}$ Sobre la relación entre Oliverio Girondo y la generación del 40 se puede ver Gaspar Pío del Corro, Oliverio Girondo: los límites del signo (Buenos Aires: García Cambeiro, 1976), pp. 82-86. 
tonos de desengaño con lo inmediato y de nostalgia de otro reino menos susceptible a los accidentes del azar y a la falta de significado:

Esperadme, esperadme, criaturas del rocío
porque despertaré
y hermoso será subir, bajo idéntico tiempo,
las altas graderías de la ciudad del sol y las tormentas,
y repetir aún, sin desamparo, las radiantes
edades que la tierra enamora

Con Las muertes, de 1952, Orozco enriquece su léxico y su repertorio de recursos retóricos. También experimenta con un grado excepcionalmente alto de literariedad, que confiere a Las muertes «algo de ejercicio de estilo" ${ }^{8}$. En nuestra consideración de Orozco, lo más notable del libro no son estas modificaciones, sino la continuidad del proyecto de una poesía comunicante entre reinos. Aquí, la otra realidad con la que se busca un contacto es la de la muerte, representada por ciertos individuos de muerte ejemplar. Sus decesos cobran los significados que les otorgan las obras literarias de las que surgen algunos, $o$, en el caso de figuras históricas y legendarias, lo que el pueblo transmisor ha visto en ellas. Las muertes derivadas del folklore interesan, en particular, porque demuestran el gran acopio de materiales legendarios y míticos que ya domina la autora en su búsqueda de arquetipos y símbolos de toda clase.

Si el lector lee no fijándose específicamente en las formas verbales, es fácil obtener la impresión de que cada poema va dirigido hacia un muerto. En efecto, tal arreglo es el más común entre los poemas del libro. Sin embargo, existen sutiles variantes entre los textos, y dentro del espacio de un solo texto, que testimonian uno de los principios rectores de la poesía de Orozco: para vincular mundos, el poeta tiene que valerse de gran número de estrategias, además de poseer muchos conocimientos especiales.

Uno de los poemas más típicos del libro es "Carina», que desarrolla los significados posibles en la muerte del personaje de un drama de Crommelynck $^{9}$. El yo se dirige al personaje nombrado e invocado - llamadopor el título del texto. Trama, en torno a su muerte, una larga meditación. Una vez más, al vislumbrar otro mundo, siente y expresa una viva insatisfacción con el mundo de los seres humanos. El yo añora un contacto más íntimo e intenso con la muerta así convidada como, entre otras cosas, un refugio de las nimiedades y la arbitrariedad del cuerpo que constituyen las caracterísicas más repulsivas de lo cotidiano:

\footnotetext{
${ }^{8}$ Liscano, p. 21.

9 Orozco, "Carina", en su Obra poética, pp. 57-58.
} 
Déjame entre las manos el último suspiro para envolver en cierzo el desprecio que rueda por mi cara, el asco de mirar la cenagosa piel del día en que me quedo.

La única excepción al formato yo-poético-a-tú-Carina es el epígrafe. Aquí Carina tiene la oportunidad de hablar — de llamar a este mundodesde su reino más bello y significativo (en la práctica, esta comunicación se logra extrayendo una cita del drama en que aparece Carina como personaje).

Una muestra, por otra parte, de las variantes posibles dentro de este esquema fundamental -invocar a un muerto- la ofrece «El pródigo» ${ }^{10}$. El pródigo enfocado aquí no es solamene el hijo pródigo que aparece en las Escrituras, sino que se figura más ampliamente como un signo del ser que ha desvirtuado las posibilidades que en otra época tenía. El poema que se elabora en torno a este arquetipo o leyenda se parece en su estructura a "Quienes rondan la noche», de la colección anterior, y ejemplifica, en efecto, un módulo frecuente en la producción de Orozco.

Todas las estrofas de "El pródigo», con excepción de la última, van dirigidas a un oyente o unos oyentes que no se han iniciado en las comunicaciones entre reinos. No son tan difíciles de convencer como el tú de "Quienes rondan la niebla». El yo supone que se aceptará la noción de un contacto con el personaje mítico, pero la falta de iniciación de la audiencia se patentiza en la explicación detallada de los fenómenos que tiene que dar el yo. Los oyentes, además, necesitan del yo como vaso comunicante para lograr un vínculo con el pródigo.

Durante los primeros doce versos, el yo prepara el ambiente para recibir al arquetipo, meditando sobre su leyenda y comentándola como un médium que desarrolla asociaciones para lograr una relación de empatía con el espíritu que se va a convocar. A partir del verso 13, el yo funciona como un médium en contacto con el convidado; obtiene respuestas a preguntas hechas sobre la condición del ente:

¿Hay algún sitio donde la libertad levante para él su desafío?

Allí está su respuesta: una furiosa ley sin paz y sin amparo.

También propio de un médium es la capacidad del yo de ver y a la vez describir dètalladamente a los no iniciados la vida del pródigo en el espacio que habita:

Pero noche tras noche,

mientras la sed, el hambre y el deseo dormitan junto al fuego como errantes mendigos que soñaran una fábula espléndida,

otras escenas vuelven tras el cristal brumoso de su llanto.

${ }^{10}$ Orozco, «El pródigo», en sur Obra poética, pp. 75-76. 
La última estrofa presenta una transición típica en la obra de Orozco. El yo ya no se dirige a los de aquí y ahora, a los que necesitan saber cómo son los otros mundos, sino a los entes y las fuerzas que se encuentran en tal zona. En este caso se dirige a los poderes («redes») que podrían dificultar el paso del pródigo en los recorridos que le son necesarios:

¡Oh redes, duras redes que intentáis contener el viento de septiembre: permitidle pasar!

No vino por perdón: no le obliguéis a expiar con el orgullo.

No vino por condena: no le obliguéis a amar con indulgencia.

Con Los juegos peligrosos (1962), el carácter shamanístico de la poesía de Orozco, siempre discernible en la construcción del yo y el tú o vosotros poéticos, florece al nivel más visible de las alusiones. A éstas las resume Guillermo Ara: «Maneja [Orozco] símbolos astrales, artilugios de la magia, recursos de cartomancia, talismanes, claves oníricas, alucinaciones y sutiles sugerencias contenidas en objetos familiares o en la palabra, sus resonancias crípticas y su poder de ensalmo».

El juego peligroso, poéticamente, consiste en el levantamiento de la restricción léxica que antes había prohibido los términos privativos al ocultismo, a la mística o a lo sobrenatural. La decisión de permitir tales referencias responde, sin duda, a motivos de la autora; en vez de especular sobre éstos, es más indicado trazar las consecuencias. El riesgo es el de producir un texto efectista, sensacionalista. Pero el consenso crítico es que Orozco se ha superado con los textos de 1962, juicio fácil de compartir $^{11}$. Se percibe que el verso de Orozco ahora puede sostener los elementos potencialmente sensacionalistas porque las estructuras retóricas que ha ido dominando la autora forman un armazón ya seguro y señalan al lector que se trata de una poesía «seria».

La evidencia para apoyar tal suposición es que las situaciones discursivas de Los juegos peligrosos son las ya elaboradas. El yo iniciado puede guiar, aconsejar y orientar al tú mientras establece contactos extraordinarios. En «Cartomancia», primer poema del libro, un vidente explica y comenta la lectura de un destino mediante una baraja Tarot. Como en «El pródigo» y otros casos anteriores, el yo formula pronunciamientos místicos y meditaciones divagantes análogos a las frases emitidas por los médiums para «imantar vibraciones». "Para hacer un talismán» (pp. 3334) y. «Para destruir a la enemiga» (pp. 43-45) vienen en forma de ins-

11. Se puede ver, por ejemplo, el juicio emitido por Ara, tomo 1, p. 141, de su obra antes citada, según el cual la innovación poética que emprende Orozco «se hace efectiva» en Los juegos peligrosos. 
trucciones. El tú, al verse amenazado por fuerzas malévolas, ha acudido a un iniciado, y los consejos que recibe constituyen el texto del poema: «nómbrala y mátala. / Y no olvides sepultar la moneda» (p. 44).

Vuelve también la otra construcción típica de Orozco, en que el yo habla dirigiéndose a otra realidad. Para dar una muestra de las formas vocativas con que se llama y nombra a otros seres: "día maldito" (de «Día para no estar», pp. 29-30), «Madre» (ente nocturno apelado en «Si me puedes mirar», pp. 35-38), una «estatua de sal» (a quien se recurre en «La caída», pp. 39-40) y «Corazón repudiado» (a quien se dirigen las últimas dos estrofas de «El adiós», pp. 31-32). Las respuestas que emiten estos seres sólo se saben por medio de la intervención del yo, de cuyos servicios invocadores y traductores dependen tanto el tú como el lector.

Museo salvaje, de 1974, la siguiente colección poética ( $E l$ sol es otra oscuridad, 1967, es de narrativa) no difiere tanto de su predecesor como las tres primeras colecciones. Como en Los juegos peligrosos, las alusiones a lo otro son eclécticas, incluyendo la cultura del médium occidental, las ciencias ocultas en sus manifestaciones mundialmente dispersas (es cada vez más evidente el vasto acopio de conocimientos que posee Orozco) y la magia campesina de talismanes y de amuletos. El arreglo estructural del poema sigue siendo, en varias combinaciones, del yo al tú no iniciado o del yo al otro mundo.

Cantos a Berenice (1977) es una serie de poemas más ligados por un concepto global y por características formales constantes a lo largo de la colección ${ }^{13}$. No hay variantes en el tú o vosotros, sino que cada poema presenta una yo poética que se dirige a su gata, ya muerta, con quien había cultivado una capacidad de vincularse con otras realidades -en suma, con su familiar de hechicera-. Más allá de su unidad formal, el libro introduce una nota nueva al especificar la naturaleza de la relación entre yo y tú y de su magia compartida. En los dos libros de poesía anteriores, el yo podría ser un shaman, un vidente, un espiritista o un mago oriental; las presencias llamadas tampoco son de una sola clase determinada. En Cantos a Berenice se asigna una importancia especial a la relación entre la hechicera y la familiar, en quien ha invertido gran parte de sus fuerzas y con quien necesita reestablecer el contacto. Como se sabe, criar una felina como espíritu familiar es atributo de las brujas en el con-

12 Orozco, «Cartomancia», en su Los juegos peligrosos (Buenos Aires: Losada, 1962), pp. 9-13. Las otras referencias a esta colección aparecerán en el texto con la paginación correspondiente a esta edición.

${ }_{13}$ Orozco, Cantos a Berenice (Buenos Aires: Sudamericana, 1977), señala su carácter de serie continua enumerando, pero no titulando, los poemas. Las citas de esta obra llevarán la paginación correspondiente a esta edición. 
cepto popular. Orozco aumenta esta asociación con lo femenino llamando la atención sobre el sexo de hechicera y familiar. Las formas morfológicas recalcan esta constante: «tú, mi otra yo misma» (p. 45), "otras nosotras mismas» (p. 42), «entre nosotras» (p. 50), entre muchos ejemplos. Insiste la yo que, como «la bruja y su emisaria», las dos no necesitan los animales que típicamente se asocian con los magos masculinos: «No tuvimos más búho que la vigilia alerta en el fondo del sueño / ni más sapo lacayo que la ráfaga fría para ahuyentar las duendes» (p. 41). Hay un esfuerzo por relacionar a Berenice con ejemplares figuras femeninas comunes en el pensamiento ocultista: «Esfinge o sibila doméstica» (p. 25), «la naturaleza» (p. 37), «hija del Sol» (p. 25).

Esta insistencia en la femineidad compartida entre tú y yo corresponde a una preocupación muy presente en la discusión intelectual de los últimos años: el redescubrimiento y la revalorización de la cultura femenida. Ha habido un gran interés por las formas diversas de la mujer "sabia», la que se mantiene en contacto con las fuerzas ocultas y las utiliza. Cantos a Berenice constituye, entre muchas otras cosas, un homenaje a las manifestaciones de la maga, desde la hechicera casera y amante de su gata que es la yo hasta las grandes dominadoras de los poderes mágicos. Las tradiciones del antiguo Medio Oriente merecen un énfasis especial, y no sólo por la obvia razón de que en Egipto se rendía culto a un dios-gato (aludido frecuentemente en los textos). La región alrededor de la extensión oriental del Mediterráneo es la que ha despertado mucho interés por su acopio de tradiciones en torno a las diosas y semidiosas semitas, las fabulosas reinas orientales, con sus conocimientos de encantos y maleficios, las pitonisas y las sacerdotisas de cultos diversos. Berenice (y no la yo, que sigue siendo más actual y casera) es la representante de este ambiente de ocultismo femenino, aludido en versos tales como:

Tú reinaste en Bubastis con los pies en la tierra, como el Nilo, y una constelación por cabellera en tu doble del cielo (p. 25).

Aún conservas intacta, memoriosa, la marca de un antiguo sacramento bajo tu paladar tu sello de elegida, tu plenilunio oscuro,

la negra sal del negro escarabajo con el que bautizaron tu linaje sagrado y que llevas, sin duda, de peregrinación en peregrinación (p. 33).

Los últimos dos cantos patentizan otra característica, que dará la nota de mayor innovación a Mutaciones de la realidad (1979) y La noche a la 
deriva (1983) ${ }^{14}$. Al terminar el acto de llamado a Berenice, su dueña revela una incertidumbre angustiada acerca de su capacidad de alcanzar o aun de figurarse a aquélla. Pierde la autoridad de la maga para expresar su insatisfacción con sus conceptos de la perduración del alma: «¿No hay otro cielo para buscarte? / ¿No hay acaso un lugar, una mágica estampa iluminada...?» (p. 70). Cuestiona su poder de penetrar entre mundos: «Tal vez sea imposible mi cabeza, ni un vacío mi voz, / algo menos que harapos de un idioma irrisorio mis palabras» (p. 73).

Tal ansiedad insegura por parte de la invocadora, que llama a un muerto sin confiar en su habilidad de comunicarse con él, dinamiza varias hermosas composiciones elegíacas de los libros de 1979 y 1983. Sin olvidar que ambas colecciones continúan los diversos tipos de texto ya desarrollados por Orozco, enfocaremos la elegía desesperada por ser el elemento de más reciente y notable aparición.

Un ejemplo muy logrado lo ofrece «Crónica entre dos ríos» (Mutaciones, pp. 49-56), poema conmemorativo que va dirigido a un hermano muerto. Como es frecuente en la nueva forma elegíaca, el individuo nombrado en la dedicatoria es, por todas señas, el modelo del tú a quien llama la yo: un ser querido cuya pérdida motiva la elaboración del texto. Hay poco artificio poético en la construcción de la relación tú-yo, en contraste con el libro más «literario» de Orozco, Las muertes, cuya voz conmemora personajes históricos, literarios o míticos, elegidos por su ejemplaridad. En las elegías inseguras, de más reciente aparición, la voz llama a muertos con quienes ha vivido experiencias íntimas, impelido por el anhelo de reanudar el vínculo.

Es notable que la hermana del muerto en «Crónica» no confía en su voz para conectarse con su ser perdido, y recurre a conductas que asumiría cualquier individuo en su situación: visualiza a su hermano y recorre en memoria los tiempos compartidos:

Me estabas esperando en esa madrugada de Congonhas desde hacía cuatro años

Con tu capote gris parecías un pájaro aterido revoloteando bajo sobre la platoforma.

Al llegar al momento presente, la hermana expresa la enorme dificultad de reanudar el contacto. Agotados los recuerdos, «aquí termina el viaje. Aquí donde se separan estos ríos...». Recurre, entonces, no a un rito, sino a un texto que existe en la realidad y contiene palabras que podrían ser las del muerto, de poder éste responder: «yo busco en mi libro

${ }_{14}$ Orozco, Mutaciones de la realidad (Buenos Aires: Sudamericana, 1979), y La noche a la deriva (México: Fondo de Cultura Económica, 1983). La paginación de las citas corresponderá a estas ediciones. 
unas palabras, una señal cualquiera, y respondes con Eliot». El persistente lenguaje «mágico» (p. ej., «la boca quemada por las brasas de las absoluciones») recuerda los poderes atribuidos al vate y hace más patética la incapacidad de la voz poética de utilizar tales dones para alcanzar a su muerto. Se ve reducida a técnicas de consuelo no sólo cotidianas, sino también ineficaces; termina el poema expresando su insatisfacción con «la rota alcancía del recuerdo».

«Por mucho que nos duela» (La noche a la deriva, pp. 34-37) constituye otro ejemplo digno de esta forma conmemorativa que testimonia una enorme frustración comunicativa. La combina con la celebración de la cultura y la intimidad femenina que apareció en Berenice (la misma síntesis ocurre también en «Recoge tus pedazos», pp. 16-17). La que llama y su muerta querida compartieron en vida un fuerte lazo específicamente de mujer a mujer. La femineidad de su vínculo se mantiene presente por la abundancia de formas léxicas que marcan el género femenino. La urgencia de reestablecer esta unión extraordinaria y el temor de fracasar ante la barrera de la muerte generan la tensión primordial del poema. La voz se dirige a su amiga perdida justamente para «decirle» que han fallado sus poderes invocadores y la posibilidad de hacerse escuchar:

Mi mano, al encuentro de la tuya, no recibe respuesta, como si resbalara por la desnuda y ciega superficie de un espejo que borra.

Mis palabras son como vidrios transparentes trizados contra un muro.

Tales poemas, en los que el acto de llamar entre mundos es un intento desesperado, no cancelan la seguridad con que anteriormente la voz poética convocaba a seres de otra realidad. Orozco sigue publicando poemas en que la invocación tiene éxito. "Rehenes de otro mundo» (Mutaciones, pp. 33-34) es una elegía del tipo de Las muertes, mientras que en «En tu inmensa pupila» (Noche, pp. 7-8) la invocadora goza de un contacto con la apelada: «Me reconoces, noche, / me palpas, me recuentas...» Dadas estas circunstancias, sería más acertado decir que las últimas colecciones presentan, en su variedad, todos los aspectos del fenómeno de la invocación del vate. El acto de llamar para el más allá puede ser la realización de ciertas convenciones literarias, lo cual es el caso en las elegías a muertos ejemplares, probablemente los textos menos distintivos y originales de Orozco. Más interesa ver el uso de la invocación para lograr contactos mágicos que testimonian el vigor de la tradición vática. Los poemas en que la voz establece una comunicación exitosa tienen, como el otro rostro de un mismo proyecto, los en que la voz que llama desfallece ante ciertas barreras siempre impenetrables. 
